\title{
Assessing the Predictive Ability of Sovereign Default Risk on Exchange Rate Returns
}

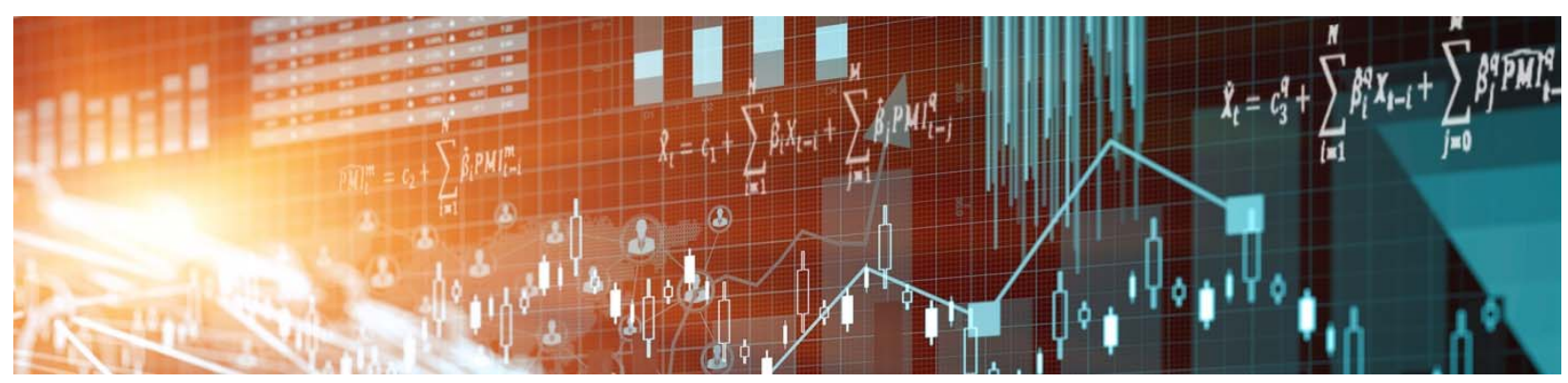

by Claudia Foroni, Francesco Ravazzolo and Barbara Sadaba 
Bank of Canada Staff Working Paper 2017-19

May 2017

\title{
Assessing the Predictive Ability of Sovereign Default Risk on Exchange Rate Returns
}

\author{
by \\ Claudia Foroni, ${ }^{1}$ Francesco Ravazzolo ${ }^{2}$ and Barbara Sadaba ${ }^{3}$ \\ ${ }^{1}$ Deutsche Bundesbank \\ claudia.foroni@bundesbank.de \\ 2Free University of Bozen/Bolzano \\ 3International Economic Analysis Department \\ Bank of Canada \\ Ottawa, Ontario, Canada K1A 0G9 \\ bsadaba@bankofcanada.ca
}




\section{Acknowledgements}

We thank Michiel de Pooter, Barbara Rossi, Marcin Jaskowski, Gerdie Everaert, Job Swank, Louis Morel and conference and seminar participants at the Bank of Canada, Norges Bank, the 23rd Symposium of the Society for Nonlinear Dynamics and Econometrics, the 3rd Annual Conference of International Association for Applied Econometrics, the 21st International Conference on Computing in Economics and Finance and the 69th European Meeting of the Econometric Society for very useful comments. The views expressed in this paper are those of the authors. No responsibility for them should be attributed to the Deutsche Bundesbank or the Bank of Canada. 


\begin{abstract}
Increased sovereign credit risk is often associated with sharp currency movements. Therefore, expectations of the probability of a sovereign default event can convey important information regarding future movements of exchange rates. In this paper, we investigate the possible pass-through of risk in the sovereign debt markets to currency markets by proposing a new risk premium factor for predicting exchange rate returns based on sovereign default risk. We compute it from the term structure at different maturities of sovereign credit default swaps and conduct an out-of-sample forecasting exercise to test whether we can improve upon the benchmark random walk model. Our results show that the inclusion of the default risk factor improves the forecasting accuracy upon the random walk model at short forecasting horizons.
\end{abstract}

Bank topics: Exchange rates; Econometric and statistical methods; International financial markets

JEL codes: C22; C52; C53; F31

\title{
Résumé
}

Un accroissement du risque souverain est souvent associé à de fortes variations des taux de change. Du coup, les anticipations quant à l'éventualité d'une défaillance souveraine peuvent apporter de l'information utile sur les mouvements futurs des taux de change. Dans cette étude, nous nous interrogeons sur la possible transmission aux marchés des changes du risque présent sur les marchés des titres souverains et proposons de prévoir les rendements sur le marché des changes à l'aide d'un facteur de prime de risque fondé sur le risque souverain. Nous calculons ce nouveau facteur à partir de la structure par terme des taux d'intérêt pour les différentes échéances de swaps sur défaillance relatifs aux titres d'emprunteurs souverains et établissons des prévisions hors échantillon pour vérifier si notre modèle réussit à faire mieux que la marche aléatoire, le modèle de référence. Nos résultats montrent que la prise en compte du risque de défaillance se traduit par une amélioration de la qualité des prévisions à des horizons rapprochés.

Sujets : Taux de change ; Méthodes économétriques et statistiques ; Marchés financiers internationaux

Codes JEL : C22 ; C52 ; C53 ; F31 


\section{Non-Technical Summary}

Exchange rates have been known to be nearly impossible to predict. Later attempts to beat the no-predictability benchmark model using economic variables derived from theoretical exchange rate models find a general failure of these models, demonstrating that the so-called "Meese and Rogoff" puzzle is not easily solved. However, in the same studies, Meese and Rogoff (1983a,b) provide a potential explanation for their results: time-varying risk premia could be an important determinant of their findings. This view is further supported by the work of Hodrick (1989), who argues that risk premia should be included in rational expectations models that study exchange rates as an asset market equilibrium. More recently, Alvarez et al. (2009) build on the well-known observation by Cochrane (2001) that most returns and price variations come from variations in risk premia, and develop a model of exchange rates that shows compelling evidence that variation in risk premia is a prime mover behind variation in asset prices. All this evidence directs our attention to the critical role played by risk premia in exchange rate determination.

In this paper, we investigate the role of risk premia from a new angle. We focus on the predictive relationship between exchange rates and expected sovereign default risk, and we construct a new forecasting model based on that. More specifically, we contribute to the existing literature by investigating whether the inclusion of expected sovereign default risk as a new source of risk premium can explain future movements of exchange rates. In our empirical assessment, we evaluate whether the inclusion of expected sovereign default risk for 10 economies - 7 advanced and 3 emerging economies - in relation to that of the U.S. helps improve out-of-sample forecasts of exchange rate returns. We obtain our measure of expected sovereign default risk from the term structure of a cross-section of sovereign credit default swap (SCDS) spreads at four different maturities over the period from 2012 to 2015.

Our findings suggest that relative sovereign default risk perceptions are important for predicting exchange rate movements, especially at shorter horizons. To be precise, we find strong evidence of predictability of exchange rates by the default risk model at the horizon of one day ahead. 


\section{Introduction}

Since the seminal work of Meese and Rogoff (1983a,b, 1988), exchange rates have been known to be nearly impossible to predict. Later attempts to beat the random walk (RW) benchmark using economic variables derived from theoretical exchange rate models find a general failure of these models, demonstrating that the so-called "Meese and Rogoff" puzzle is not easily solved (see Rossi (2013) for a review of the literature). However, in the same studies, Meese and Rogoff $(1983 a, b)$ provide a potential explanation for their results: time-varying risk premia could be an important determinant of their findings. This view receives further support in subsequent works. Hodrick (1989) argues that risk premia should be included in rational expectations models that study exchange rates as an asset market equilibrium. More recently, Alvarez et al. (2009) build on the well-known observation by Cochrane (2001) that most returns and price variations come from variations in risk premia, and develop a model of exchange rates that shows compelling evidence that variation in risk premia is a prime mover behind variation in asset prices. All this evidence directs our attention to the critical role played by risk premia in exchange rate determination.

In this paper, we investigate the role of risk premia from a new angle. We focus on the predictive relationship between exchange rates and expected sovereign default risk, and we construct a new forecasting model based on that.

Expected sovereign default risk constitutes an example of markets' expectations regarding the probability of rare but extreme economic disasters, such as a default event. These extreme events correspond to bad economic times and therefore they can matter disproportionately for the determination of asset prices despite their low probability of occurrence. This is formalized in the Rietz-Barro hypothesis (Rietz, 1988; Barro, 2006), which states that the possibility of rare disasters such as an economic depression is a major source of risk premia in asset prices. ${ }^{1}$ In a recent paper, Farhi and Gabaix (2016) develop a theoretical model of exchange rates in which they allow for extreme negative economic downturns to occur at any point in time. They show that countries differ in terms of their riskiness and this translates into the extent to which

\footnotetext{
${ }^{1}$ It is important to note that this literature differs from the so-called peso problem literature (Lewis, 2008), which assumes no risk premia.
} 
their exchange rates would depreciate should a default occur. Building on this hypothesis, we contribute to the existing literature by investigating whether the inclusion of expected sovereign default risk as a new source of risk premium can explain future movements of exchange rates.

In our empirical assessment, we evaluate whether the inclusion of expected sovereign default risk for 10 economies - 7 advanced and 3 emerging economies - in relation to that of the U.S. helps improve the out-of-sample (OOS) forecast of exchange rate returns. We obtain our measure of expected sovereign default risk from the term structure of a cross-section of sovereign credit default swap (SCDS) spreads at four different maturities over the period from 2012 to 2015. SCDS contracts act as a form of insurance to hedge against investors' risk-neutral probabilities of extreme credit events impinging on sovereign issuers. Therefore, by exploiting the term structure of SCDS spreads at different maturities, one can infer credit market default expectations embedded in market data (Pan and Singleton, 2008). Moreover, we stress that what matters is the perception of the risk in one country relative to the other benchmark countries (i.e., the U.S.), and in our empirical approach we compute the default risk factor using a one-factor term structure model of SCDS spreads market data for each country in real time and derive a relative measure by taking the difference across countries. Our empirical approach assumes that one factor is enough to account for the time-series dynamics of the term structure of SCDS spreads. This modeling choice is motivated by the fact that the series of SCDS contracts at different maturities present a high level of co-movement across the series, which is confirmed by a principal components analysis.

Our findings suggest that relative sovereign default risk perceptions are important for predicting exchange rate movements, especially at shorter horizons. To be precise, we find strong evidence of predictability of exchange rates by the default risk model at the horizon of one day ahead. In 9 out of 10 cases considered in our analysis, our model based on the default risk factor obtains a better forecasting performance with respect to the RW benchmark. In six cases, the improvement is statistically significant. For the weekly forecast horizon, results are more mixed, with the default risk factor model improving upon the benchmark for only a few cases. As we move to the longest forecast horizon, the predictability disappears. Finally, when we account for the forecasting performance of our models over time, we find that for the default risk model, 
most of the gains occur in the second half of 2013 for several countries. At that time, the U.S. economy showed the first signs of recovery, which changed the relative risk perception of other countries, and this helps to predict the beginning of the appreciation of the dollar. We also document large gains at the end of 2014 and in the first quarter of 2015, when the European Central Bank (ECB) started its quantitative easing (QE) program.

Our empirical approach is further supported by another strand of literature that explores the implications of a sovereign default for exchange rate determination. In an early work, Krugman (1979) shows how large, unsustainable budget deficits can lead to currency attacks. Reinhart (2002) presents a comprehensive study on the relationship between actual sovereign defaults and currency crisis. She finds a strong association between the two events, and that sovereign default events often lead to currency crises. Recently, Lukkezen and Bonam (2014) developed an extended New Keynesian model to allow for sovereign default risk and found that a rise in default expectations triggers a depreciation of the nominal exchange rate.

Additionally, our work contributes to extending the literature that explores the role of risk factors as non-traditional drivers of exchange rate movements. This literature has, so far, focused mainly on the in-sample analysis. An example of this is Lustig et al. (2011), who are the first to show that large co-movements among exchange rates of different currencies support a risk-based view of exchange rate determination. Furthermore, Verdelhan (2015) finds that two risk factors account for a substantial share of individual exchange rate time-series dynamics in developed countries. He also presents some economic interpretation for these factors by naming them the dollar and the carry factor. The dollar factor captures the average change in the exchange rate of all other currencies relative to the U.S. dollar, while the carry factor refers to the change between portfolios of high and low interest rate currencies. Our work also adds to the existing literature in a similar fashion by identifying a specific class of risk in the risk premia of exchange rates. Finally, another study closely related to our present work, Della Corte et al. (2015) conducts an in-sample analysis on the explanatory power of SCDS spreads in deviations from the corresponding U.S. spreads on exchange rate returns. They find a strong link between exchange rate changes and SCDS spreads changes and, in particular, that global credit risk is an important determinant of exchange rates. 
Our results also contribute to the analysis of the importance of sovereign default risk for developed countries' currencies. Historically, the analysis of the relationship between a country's creditworthiness and currency crashes was centered on developing countries. However, in recent years, markets have started paying attention to measures of default risk perceptions also for developed countries that are a long way from a default event and for which the economic outlook has remained stable. Our results present evidence to support the notion that expectations regarding sovereign default risk also matter for developed economies.

The outline of the paper is as follows. Section 2 describes the SCDS spreads term structure model. Section 3 presents the data and the sample specification. The empirical specification of our forecasting model is discussed in Section 4 and results are presented in Section 5. Section 6 describes some robustness checks and Section 7 concludes.

\section{A standard model of the default risk factor}

In this section, we describe a standard reduced-form pricing model of credit default swap (CDS) spreads that we use to obtain the implied default risk factor following the work of Pan and Singleton (2008). In particular, we extract the risk factor by way of the term structure of a cross-section of CDS spreads at four different maturities. The underlying assumption is that CDS spreads at different maturities are driven by one latent factor that is specific to the sovereign default risk of each country. The one-factor modeling choice is motivated by a principal components analysis conducted on the term structure of CDS spreads. In Table 1, we show that it is indeed the first principal component that presents the highest share explained of the total variance in the data for all regions included in our sample.

\subsection{The model}

The price of a CDS contract of maturity $\tau$ at time $t$ is defined by the ratio of the so-called default leg and the fixed leg, such that

$$
c d s_{\tau t}=\frac{L_{\tau t}^{\text {default }}}{L_{\tau t}^{\text {fixed }}}
$$

The default leg is equal to the expected payment that the buyer of the CDS contract will 
receive from the issuer in case of a default event. The fixed leg, in contrast, is the sum of discounted CDS premium payments, taking into account the probability that default never occurs, plus a one-time accrued premium payment made at the time of default. This yields

$$
\begin{aligned}
L_{\tau t}^{\text {default }} & =(1-\pi) \int_{t}^{\tau} E_{t}^{\mathbb{Q}}\left[e^{-\int_{t}^{v} \lambda_{s} d s} \lambda_{v}\right] d v \\
L_{\tau t}^{\text {fixed }} & =\frac{1}{4} \sum_{j=1}^{4 \tau} E_{t}^{\mathbb{Q}}\left[e^{-\int_{t}^{\frac{1}{4} j} \lambda_{s} d s}\right]+\int_{t}^{\tau} E_{t}^{\mathbb{Q}}\left[e^{-\int_{t}^{v} \lambda_{s} d s} \lambda_{v}\right]\left(v-\tau_{I(t)}\right) d v
\end{aligned}
$$

so that

$$
c d s_{\tau t}=\frac{(1-\pi) \int_{t}^{\tau} E_{t}^{\mathbb{Q}}\left[e^{-\int_{t}^{v} \lambda_{s} d s} \lambda_{v}\right] d v}{\frac{1}{4} \sum_{j=1}^{4 \tau} E_{t}^{\mathbb{Q}}\left[e^{-\int_{t}^{\frac{1}{4} j} \lambda_{s} d s}\right]+\int_{t}^{\tau} E_{t}^{\mathbb{Q}}\left[e^{-\int_{t}^{v} \lambda_{s} d s} \lambda_{v}\right]\left(v-\tau_{I(t)}\right) d v}
$$

where $\lambda_{t}$ is the default risk factor and $\pi$ the recovery rate upon default. $\tau_{I(v)}$ represents the date at which the last premium payment was paid before the default occurred. It is possible that default takes place between two payment dates; for instance, between times $\tau_{j}$ and $\tau_{j+1}$ where $j=I(v)$. In that case, $v-\tau_{I(v)}$ is the period over which the protection buyer has to pay an accrued premium, given that default happened at $v$. In line with Pan and Singleton (2008), who argue that a constant recovery rate assumption is not unreasonable for the sovereign debt market, we keep it constant and fixed at 40\%. To solve eq.(3), expectations under the riskneutral probability measure $\mathbb{Q}$ have to be computed. Using the moment-generating functions given in Duffie and Garleanu (2001), the expectations can be expressed as

$$
\begin{aligned}
E_{t}^{\mathbb{Q}}\left[e^{-\int_{t}^{v} \lambda_{s} d s} \lambda_{v}\right] & =e^{\Phi(v-t, 0)+\Psi(v-t, 0) \lambda_{t}\left[\Phi_{u}(v-t, 0)+\Psi_{u}(v-t, 0) \lambda_{t}\right]} \\
E_{t}^{\mathbb{Q}}\left[e^{-\int_{t}^{v} \lambda_{s} d s}\right] & =e^{\Phi(v-t, 0)+\Psi(v-t, 0) \lambda_{t}}
\end{aligned}
$$

where the functions $\Phi(v-t, u), \Psi(v-t, u)$ are the solutions of a set of Riccati equations and $\Phi_{u}(v-t, u)$ and $\Psi_{u}(v-t, u)$ are the corresponding derivatives, which we describe in detail in Appendix B. Finally, the default risk factor $\lambda_{t}$ follows a Vasicek (1977) model with a constant volatility structure. The diffusion process for the factor is as follows:

$$
d \lambda_{t}=\Lambda\left(\lambda_{t}-\theta\right) d t+\sigma d W_{t}
$$

where $W_{t}$ is an independent standard Brownian motion under the empirical probability measure $\mathbb{P}$. To price a derivative, we need to obtain the stochastic process for the factor under the 
risk-neutral probability measure $\mathbb{Q}$ (to ensure the non-arbitrage condition). To this end, we transform the diffusion process such that it is equal to

$$
d \lambda=\Lambda^{*}\left(\lambda-\theta^{*}\right) d t+\sigma d W_{t}^{*}
$$

where $\Lambda^{*}=\Lambda$ and $\Lambda^{*} \theta^{*}=\Lambda \theta+\sigma$.

To implement the model, we cast it in state-space form. The CDS spreads $y_{\tau t}$ for maturity $\tau$ (where $\tau=1,3,5,10$ ) in period $t$ can be expressed by the following latent factor model

$$
y_{\tau t}=c d s\left(\lambda_{t}, \Theta\right)+\varepsilon_{\tau t}
$$

where $c d s\left(\lambda_{t}, \Theta\right)$ is the price of the CDS defined in eq.(3) and it is a nonlinear function of the latent factor $\lambda_{t}$. The vector of hyper parameters is given by $\Theta$ and $\varepsilon_{\tau t}$ is the measurement error term specified as white noise Gaussian processes $\varepsilon_{\tau t} \sim W N\left(0, \sigma_{\varepsilon_{\tau}}^{2}\right)$. The latent factor $\lambda_{t}$ follows an $A R(1)$ process,

$$
\lambda_{t}=\phi_{t}^{0}+\phi_{t}^{1} \lambda_{t-1}+u_{t}
$$

where $\phi_{t}^{0}$ and $\phi_{t}^{1}$ are defined as $\phi_{t}^{0}=\theta\left(1-e^{-\kappa \Delta t}\right)$ and $\phi_{t}^{1}=e^{-\kappa \Delta t}$, with $\Delta t$ being the time step between observations. The error term $u_{t}$ is a white noise Gaussian process $u_{t} \sim W N\left(0, \sigma_{\eta}^{2}\right)$. We estimate the Gaussian nonlinear model given by eqs.(7) and (8) and obtain the factors using the extended Kalman filter. In Table 2, we present the estimated maximum likelihood parameters of the model. The state-space representation of the model is shown in Appendix C.

\section{Data and sample description}

In this section we describe the data, present some summary statistics and discuss the sample choice used in our empirical analysis.

We use data for seven developed economies: Norway, Sweden, Denmark, Japan, United Kingdom, the euro area and Australia; and three emerging economies: South Africa, Mexico and Indonesia. The benchmark country is the U.S. These ten economies constitute an interesting sample for at least two reasons. First, the seven developed economies constitute the main economic regions of the developed world and they are open economies that are perfectly financially and economically integrated in the global economy. The emerging economies are less integrated 
in global financial markets, but they represent Africa, Latin America and Asia, respectively. Second, all ten countries have largely independent currencies that are among the most traded in the foreign exchange market. All data are obtained from Thomson Reuters via Datastream.

\subsection{Sample choice}

We use daily data over the period from 2 January 2012 to 11 March 2015. This gives a total of 833 daily observations. Our sample period is determined by the timing of regulatory reforms affecting the functioning of the SCDS market and the start of monetary stimulus policy programs in most of the economies in our sample.

In an attempt to reduce the destabilizing effect of excessive speculative use of SCDS instruments, European authorities introduced a ban on the uncovered or "naked" purchases of SCDS. In other words, holding SCDS contracts with no offsetting position in the underlying debt was no longer allowed. The timeline for the policy goes as follows: on 15 November 2011, the European Parliament formally adopted the proposed regulation, the final version of which was passed and announced on 14 March 2012 and finally went into effect on 1 November 2012. Changes in the trend of net notional amounts outstanding in the SCDS market since the end of 2011 show that investors started incorporating the effects of such a ban long before it officially went into effect the following year (IMF, 2013). This presents evidence that the new regulatory setting forced much of the speculative trading in SCDS out of the market, so that the prices allow for a cleaner identification of the fundamentals. A stable regulatory timeline is key to our present analysis, and thus we restrict our sample to the period after markets started pricing in the new regulatory framework and no further legal reforms were introduced.

Although the new regulation applies to trading in the European Economic Area sovereign debt obligations, new regulatory changes were indeed a more global trend. For instance, over the course of 2012, Japan introduced new regulations and amendments to existing legislation related to the over-the-counter (OTC) derivatives trade to which SCDS belong. Furthermore, most of the economies included in our sample are heavily linked to the European financial markets.

The end of 2014 and the first quarter of 2015 was the time when most of the countries in our sample started, extended or sustained their monetary stimulus policy programs. In the E.U., 
QE started by March 2015 while Denmark introduced negative rates (a sort of undercover QE) in January 2015 and Sweden in February 2015. Furthermore, in October 2014, the Bank of Japan (BoJ) decided to increase the amount of asset purchases to $¥ 80$ trillion per year. During this time, the Bank of England (BoE) decided to keep its benchmark rates at record lows and, by the end of March, to put on hold any move to increase the rates. All these events took place while the U.S. was moving in the opposite direction by ending its QE program and therefore reinforcing disparities with the rest of the largest developed economies around the world.

\subsection{Sovereign credit default swaps}

We use SCDS spreads to obtain our measure of the default risk factor. SCDS contracts are used to hedge against the default risk in the underlying sovereign bonds and therefore convey reliable information on the market-implied expectations of sovereign default; see, for example, Pan and Singleton (2008); Duffie et al. (2003); Christensen (2007); Jaskowski and McAleer (2013). Over time, this market has become highly liquid and thus provides a better measure of sovereign default risk than the corresponding bonds market, which also prices other risks such as inflation risk, or credit agencies rankings, which are often slow to react to economic changes and are inaccurate.

We use daily SCDS spreads at four different maturities: 1-year, 3-year, 5-year and 10-year, for all 10 economies included in our sample. The choice of the maturities is tailored to capture the entire range of the yield curve while ensuring the inclusion of the most liquid maturities. Contrary to the corporate case, where most of the trading is concentrated in the 5-year segment only, for sovereign reference entities, trading is more spread out across different maturities. Augustin (2014) documents that shorter maturity contracts (1-year or less) and those in the more than 1- to 5 -year segment account for roughly $87 \%$ of total volumes.

Our spreads correspond to SCDS contracts with full restructure clause, senior unsecured and denominated in U.S. dollars. Similar to Pu and Zhang (2012) and Hui and Chung (2011), for the case of the euro area, we construct two separate representative euro aggregate measures, one for the core countries - namely, France, Germany, The Netherlands and Belgium — and a second 
one for the peripheral countries-Italy, Spain, Portugal and Ireland. ${ }^{2}$

Summary statistics are presented in Table 3. Figure 1 shows the evolution of the SCDS throughout time at the different maturities. In general, the particularly turbulent period affecting sovereigns between 2012 and 2013 is clearly noticeable in the higher rates.

\subsection{Foreign exchange rates}

The exchange rate data are daily nominal spot exchange rates expressed as the price in units of the domestic currency relative to the U.S. dollar (meaning that an increase in the exchange rate is a depreciation of the domestic currency). Summary statistics are presented in Table 4.

The 10 economies included in our data and their corresponding currency names and codes are as follows: Norway — Norwegian krone (NOK); Sweden — Swedish krona (SEK); Denmark—Danish krone (DKK); Japan-Japanese yen (JPY); United Kingdom—British pound (GBP); Euro area - euro (EUR); Australia-Australian dollar (AUD); South Africa-South African rand (ZAR); Mexico-Mexican peso (MXN); Indonesia-Indonesian rupiah (IDR).

In our empirical analysis, we calculate log exchange rate changes at the daily frequency for the different forecasting horizons. We provide more details on the choice of forecasting horizons in Section 4.

\section{Forecasting exchange rate returns}

For the objective of our paper, we exploit the factors described in Sections 2 and 3, to see whether they help improve the predictability of exchange rates. We employ a linear regression framework where we regress the exchange rates on the default risk factor differentials. In this way, we explore the role of the default risk factor as a non-traditional driver of exchange rate movements.

\footnotetext{
${ }^{2}$ As customary in the sovereign debt market literature, Greece is not part of our peripheral countries sample. The explosive behavior of the Greek CDS spreads may affect our estimations. Furthermore, it underwent an actual default event in 2013 .
} 


\subsection{Design of the forecasting exercise}

We employ a recursive forecasting scheme, generating forecasts 1,5 and 20 days ahead. ${ }^{3}$ Our sample spans from 2 January 2012 to 11 March 2015. Our estimation sample stops on 7 November 2013, and we recursively expand it to produce OOS forecasts over the period 7 November 2013 to 11 March 2015. The starting date for our OOS is set one week after the bilateral liquidity swap arrangement (central bank currency swap (CBCS)) between the main six central banks was made standing. In financial markets, the CBCS involves two currencies and allows for the possibility of making the currency issued by one central bank available in the constituency of the other central bank(s) involved in the swap arrangement. Therefore, the CBCS alleviates monetary and financial instability by reducing foreign currency liquidity risk. This regulatory change is key to our analysis for at least two reasons: first, the new permanent status of CBCS is central to protecting the free movement of capital between countries and investments in different currencies; second, as for the choice of the end of our total sample period, here we choose a stable regulatory time span.

We compute our $h$ steps-ahead forecast using the factors in deviations from those corresponding to our benchmark country, the U.S. In particular, forecasts based on our default risk factor model are obtained as:

$$
\Delta s_{t+h}=\gamma+\beta_{1}\left(\Delta x_{1 t}^{D R_{d}}-\Delta x_{1 t}^{D R_{U S}}\right)+\varepsilon_{t+h}
$$

where $\Delta s_{t+h}$ is the log difference of the $h$ periods ahead (where $h=1,5,20$ ), exchange rate returns are defined as $\ln \left(S_{t+h}\right)-\ln \left(S_{t}\right)$, the default risk factor is equal to $\Delta x_{i t}^{D R_{j}}$ for country $j$, where $j=d, U S$ with $d$ being the domestic country, $\gamma$ is the drift parameter and $\varepsilon_{t+h} \sim$ $W N\left(0, \sigma^{2}\right)$.

A standard benchmark to forecast exchange rate returns $h$ steps ahead is a driftless RW model (see Rossi (2013) for a review of the literature):

$$
s_{t+h}=s_{t}+\varepsilon_{t+h}
$$

\footnotetext{
${ }^{3}$ Five days correspond to one week and 20 days to one month.
} 


\subsection{Forecasting evaluation}

To evaluate the accuracy of the forecasts produced by our models, we look at the mean squared predictive errors (MSPEs) and compare them to those produced by a RW benchmark. To evaluate whether the differences in the MSPEs between our models and the RW benchmark are significant we use the Clark and West (CW) test (see Clark and West (2007) for details on the test). The CW test is a test of OOS population-level predictability, in which under the null hypothesis, the extra parameters in the extended model are jointly equal to 0 .

While the CW test allows us to evaluate the global OOS performance of our models, we are also interested in examining the local relative performance over the OOS period. Following Welch and Goyal (2008), we investigate whether and how the squared prediction varies over time by a graphical inspection of the cumulative squared prediction error difference (CSPED):

$$
C S P E D_{k, t+h}=\sum_{s=\underline{t}}^{t} \widehat{f}_{k, s+h},
$$

where $\widehat{f}_{k, t+h}=e_{R W, t+h}^{2}-e_{k, t+h}^{2}$, with $e_{R W, t+h}^{2}$ the squared error of the RW model to predict $y_{t+h}$ and $e_{k, t+h}^{2}$ the squared error of one of the $k$ alternative models (where $k=1,2,3$ ). Increases in $C S P E D_{k, t+h}$ indicate that the model alternative to the RW benchmark predicts better at the OOS observation $t+h$.

\section{Results}

This section presents the empirical results of the forecasting performance of our models based on default risks using the framework described in Section 4.

\subsection{Forecasting performance: out-of-sample results}

In Table 5, we present the MSPEs of our proposed default risk model with SCDS factors relative to the RW benchmark for different currencies and different horizons: $h=1,5$ and 20 days ahead (which correspond to forecasting the exchange rate one day, one week and one month ahead). A ratio smaller than 1 implies that the model under consideration beats the RW benchmark at that specific horizon. Moreover, we report the p-value for the $\mathrm{CW}$ test to detect whether the 
differences in the MSPEs are statistically significant (for further details on the test, see Clark and West (2007)).

As a general remark, we find strong evidence of predictability of the exchange rates. Our default risk model outperforms the RW for all the currencies, except for the British pound, at $h=1$ forecast horizon. Moreover, in most of the cases, the improvement in predictability is statistically significant at $10 \%$ level. Even for $h=5$ and $h=20$, our results are comforting: in most cases we beat the RW, although the longer the forecast horizon, the more the significance decreases.

The larger statistical gains with p-values lower than $5 \%$ are for the Scandinavian countries. For these countries, the risk of default is small and stable over the sample; however, we stress that what matters is the perception of the risk in one country relative to the other benchmark countries (i.e., the U.S.). Compared with the U.S., for example, the Scandinavian countries were considered much safer in 2012 than at the period starting from the second half of 2013 and during the following year, when the U.S. economy showed the first signs of resilience. The perception of risk in an economy can therefore have changed over time even if economic fundamentals of the country have remained stable. Our model exploits exactly the changes in the relative risk perceptions to provide more accurate forecasts. Similar reasoning can also be applied for Australia and euro core countries.

A different story applies for the euro peripheral countries: the most acute period of the euro debt crisis was in the second semester of 2011 and in 2012, before a series of actions by the ECB from the second part of 2012 to 2014 and the quantitative easing plan from the end of 2014 stabilized and improved the sustainability of the euro peripheral countries, providing evidence of exchange rate predictability.

Mexico and Indonesia experienced a period of relative political calm during our sample, allowing risk perception to be related to economic performance and reforms more than political turmoil and providing evidence of predictability.

Finally, Japan and South Africa were respectively dominated by two major events: Abenomics for Japan and gold dynamics for South Africa as the largest exporter in the world. The short-term effects of these two phenomena on the domestic economies are not clear and our 
model provides economic gains but no statistical improvements.

\subsection{Forecasting performance over time}

Our sample period is characterized by several shocks, and especially by the European debt crisis and all the subsequent actions that followed. Such shocks might have changed the predictability of our model over time. In Figure 2, we present the CSPED to shed light on possible changes in the predictability over the OOS period. Increases in CSPED indicate that our default risk model predicts better than the benchmark.

Looking at the default factor performance, we see that most of the gains for several countries take place at the beginning of our OOS period - fourth quarter of 2013 and first quarter of 2014 - and at the end of it - fourth quarter of 2014 and first of 2015. For this middle period, the relative perception of the other countries with respect to the U.S. weakened and predictability is lost for all but Mexico and Indonesia. During the later period, default conditions relative to the U.S. did not change because of a convergence of policies of each country with those of the U.S., and therefore our model cannot exploit enough information on the default factor.

For the Scandinavian region, Norway and Sweden present the largest and only gains toward the end of the OOS period. For both, the breaking point was the end of the asset purchase program of the Federal Reserve (the Fed) in the U.S. by the end of October 2014 (point o); at this point, the CSPED changes direction and, shortly afterward, we obtain very large gains from our SCDS model. This could be related to a change in perceptions as the ECB was moving toward more stimulus and the U.S. was coming out of it. Furthermore, the persistent low oil prices were a heavy drag on Norway. In the case of Denmark, there is predictability at the beginning of the OOS period when the U.S. started to show signs of resilience, and problems in euro zone countries began to influence the Danish outlook. However, gains are lost after the Danish National Bank (DNB) raised deposit rates by the end of April 2014 (point g). Given the low inflation rates at the time, this could have been taken as a positive signal that reflected good underlying fundamentals. By mid-January 2015, when the ECB announced its quantitative easing program (point s), predictability returns as a result of fears that Denmark wouldn't be able to support its currency peg with the euro. In early February 2015, the DNB decreased 
its benchmark rates into negative territory (point t) and fears decreased, only to increase again after the ECB quantitative easing effectively started (point v).

In the case of Japan, the picture is very similar, although the reasons behind it are quite different. At the start of the OOS period, Japan was taken as a safe haven in relation to the U.S.; however, this was lost after the value added tax (VAT) rate hike in April 2014 (point f), which resulted in a large contraction in consumption and output. At that point, all gains in our SCDS model are lost. By the third quarter of 2014, while the U.S. was showing signs of resilience, Japan fell back into recession (point r) and the perception of relative default risk went up, allowing our model to exploit some of this information. This was reinforced after the Fed ended its assets-buying program (point o) and the BoJ extended its bond-buying program in October 2014 (point p).

For the U.K., all predictability is found at the beginning of the OOS period and reaches its peak by early July 2014 when gross domestic product (GDP) growth reached its highest level since the crisis (point k). After this point, the CSPED changes direction and begins its downward trend. Shortly afterward, all gains are lost forever because there was no variation in the relative perception of risk between the U.K. and the U.S.

In the case of the E.U., both core and periphery loose the initial predictability gains after the ECB cut rates into negative territory (point $\mathrm{j}$ ). The relative perception of default risk started to matter again after the Fed stopped its asset purchases (point o) and it continued to increase after the ECB announcement and implementation of its quantitative easing program (points $\mathrm{s}$ and $\mathrm{v})$.

Australia presents a similar pattern to the rest of the countries, with a clear increase in predictability after the change in policy by the Fed. As the Australian dollar serves as an investing currency in carry trade strategies, most of the observed changes can likely be explained by changes in international capital flows.

South Africa shows gains at the start of the sample, which start to fade out after the South African Reserve Bank increased the repo rates by the end January 2014 (point d), only to be regained after the Fed exited its quantitative easing program (point o).

Finally, for both Mexico and Indonesia, predictability is present through the entire sample 
period. Some of the relative risk perceptions for Mexico seem to decrease after energy reforms were made law, supporting the incumbent president's reputation (point $\mathrm{m}$ ). As expected, after the Fed ended QE, Mexico's perceived relative vulnerability increased as capital flew back to the U.S., and our model's performance improves. For Indonesia, predictability gains are overall quite high and volatile, with one large reduction in predictability in early July 2014, when a new president was elected and political uncertainty was reduced (point l).

\section{Robustness}

In this section, we verify the robustness of our results in different ways. First, we look at a different measure of our default risk factor. Second, we examine different sample frequencies for predicting exchange rates at weekly and monthly horizons. Finally, we compare our results with those obtained with a standard uncovered interest rate parity (UIP) model with short-term interest rates. The interest rate model provides a good fundamentals-based benchmark to gain a better understanding of the relative importance of our default risk factors for exchange rate determination.

\subsection{Different SCDS factor transformation}

As a first robustness check of our default risk measure, we redo our OOS forecasting estimations using an alternative measure based on a global SCDS factor computed as an equally weighted average of our default risk measure across all countries except the country being forecasted in each regression. For instance, for the forecasting regression of the Norwegian krone (NOK), the global SCDS measure is constructed with Norway excluded. This is done to allow for global influences only and rule out potential country-specific effects. Overall, the OOS predictability results shown in Table 6 for the global measure are good but significance is rather weak, especially at the weekly and monthly horizons. These results are in line with the evidence presented by Augustin (2014), who argues that during times of stress and for those countries undergoing financial turmoil, country-specific factors tend to be more relevant, while global risk factors have been found to be important for samples of more stable countries and during non-crisis periods. 


\subsection{Different sampling frequencies}

The main goal of this paper is to explore whether default risk factors and interest rate factors on a daily frequency can predict exchange rate returns over different horizons. However, one might still be interested in the performance of the model at lower frequency. Therefore, we repeat our OOS exercise using data at the weekly and monthly frequencies and 1-step-ahead horizon, and not at a daily frequency with weekly and monthly horizons as we did in the previous section. In both cases, end-of-period data are used.

Table 7 reports the corresponding results. We do not find significant predictability when looking at weekly or monthly frequency. One possible explanation is the nature of the exchange rate markets. These markets are very liquid and highly informed platforms that react very quickly to news such as country credit conditions based on macroeconomic fundamentals.

\subsection{Comparison with the UIP model}

The UIP model represents the most examined model to explain exchange rates with macroeconomic fundamentals. Therefore, it provides a good fundamentals-based benchmark to understand the predictive ability of our default risk factor model.

To estimate our interest rate factor model, we use data on 3-month interest rates, for which summary statistics are presented in Table 3 .

Forecasts based on the interest rates are computed according to the following equation:

$$
\Delta s_{t+h}=\gamma+\alpha\left(\Delta x_{t}^{I R_{d}}-\Delta x_{t}^{I R_{U S}}\right)+\varepsilon_{t+h}
$$

where $\Delta x_{t}^{I R_{j}}$ is the interest rate for the $j$ country, where $j=d, U S$, with $d$ being the domestic country, and the rest is defined as above.

The results in Table 8 show that the interest rate model provides comparable results to our default risk model only for some countries and for $h=1$. In general, the results are not very satisfactory, in line with previous results in the literature (see Rossi (2013) for a review of the literature). 


\section{Conclusions}

In this paper, we study the predictive ability of sovereign default risk to forecast exchange rate returns. By doing this, we shed new light on the importance of risk factors as drivers of international asset prices. Furthermore, we identify one specific type of risk present in currency markets: expected probabilities of rare but extreme economic disasters such as a sovereign default event. The idea is that the possibility of rare disasters such as an economic depression is a major source of risk premia in asset prices. Building on this hypothesis, we contribute to the existing literature by investigating whether the inclusion of expected sovereign default risk as a new source of risk premium can explain future movements of exchange rates.

We compute our sovereign default risk factor using a term structure model of sovereign credit default swaps assuming a fixed market-implied recovery rate in case of default. For 10 different countries, our results show, first, that the inclusion of the default risk factor improves the forecasting accuracy over the RW model, especially at shorter horizons. We find strong evidence of predictability of the exchange rates by the default risk model at the horizon of one day ahead. Second, when looking at the forecasting performance of our models over time, we find that for our default risk model the largest gains coincide with domestic and global events that affect the relative perception of a country's outlook. We conclude, then, that default risk expectations do provide accurate information regarding exchange rate movements. 


\section{References}

Alvarez, F., Atkeson, A., and Kehoe, P. J. (2009). Time-varying risk, interest rates, and exchange rates in general equilibrium. The Review of Economic Studies, 76(3):851-878.

Augustin, P. (2014). Sovereign credit default swap premia. Journal of Investment Management, 12(2):65-102.

Barro, R. J. (2006). Rare disasters and asset markets in the twentieth century. The Quarterly Journal of Economics, pages 823-866.

Christensen, J. H. E. (2007). Joint default and recovery risk estimation: an application to CDS data. mimeo.

Clark, T. E. and West, K. D. (2007). Approximately normal tests for equal predictive accuracy in nested models. Journal of Econometrics, 138(1):291-311.

Cochrane, J. (2001). Asset Pricing. Princeton University Press, Princeton, NJ.

de Jong, F. (2000). Time series and cross-section information in affine term-structure models. Journal of Business and Economic Statistics, 18(3):300-314.

Della Corte, P., Sarno, L., Schmeling, M., and Wagner, C. (2015). Exchange rates and sovereign risk. mimeo.

Duffie, D. and Garleanu, N. (2001). Risk and valuation of collateralized debt obligations. Financial Analysts Journal, 57(1):41-59.

Duffie, D., Pedersen, L. H., and Singleton, K. J. (2003). Modeling sovereign yield spreads: a case study of Russian debt. The Journal of Finance, 58(1):119-159.

Farhi, E. and Gabaix, X. (2016). Rare disasters and exchange rates. Quarterly Journal of Economics, 131(1), 1-52.

Hodrick, R. J. (1989). Risk, uncertainty, and exchange rates. Journal of Monetary economics, $23(3): 433-459$. 
Hui, C.-H. and Chung, T.-K. (2011). Crash risk of the euro in the sovereign debt crisis of 2009-2010. Journal of Banking and Finance, 35(11):2945-2955.

IMF (2013). A new look at the role of sovereign credit default swaps. Global Financial Stability Report.

Jaskowski, M. and McAleer, M. (2013). Estimating implied recovery rates from the term structure of CDS spreads. Tinbergen Institute Discussion Paper.

Krugman, P. (1979). A model of balance-of-payments crises. Journal of Money, Credit and Banking, 11:311-325.

Lewis, K. (2008). Peso problem. The New Palgrave Dictionary of Economics 2. McMillan, Hampshire, England.

Lukkezen, J. and Bonam, D. (2014). Government spending shocks, sovereign risk and the exchange rate regime. CPB Discussion Paper, No. 263.

Lustig, H., Roussanov, N., and Verdelhan, A. (2011). Common risk factors in currency markets. Review of Financial Studies, 24:3731-3777.

Meese, R. and Rogoff, K. (1983a). The out-of-sample failure of empirical exchange rate models: sampling error or misspecification? Exchange Rates and International Macroeconomics, 67105.

Meese, R. and Rogoff, K. (1988). Was it real? the exchange rate-interest differential relation over the modern floating-rate period. The Journal of Finance, 43(4):933-948.

Meese, R. A. and Rogoff, K. (1983b). Empirical exchange rate models of the seventies: Do they fit out of sample? Journal of International Economics, 14(1):3-24.

Pan, J. and Singleton, K. J. (2008). Default and recovery implicit in the term structure of sovereign CDS spreads. The Journal of Finance, 63(5):2345-2384.

$\mathrm{Pu}$, X. and Zhang, J. (2012). Can dual-currency sovereign CDS predict exchange rate returns? Finance Research Letters, 9(3):157-166. 
Reinhart, C. M. (2002). Default, currency crises and sovereign credit ratings. World Bank Economic Review, 16(2):151-170.

Rietz, T. A. (1988). The equity risk premium: a solution. Journal of Monetary Economics, 22(1):117-131.

Rossi, B. (2013). Exchange rate predictability. Journal of Economic Literature, 51(4):1063-1119.

Vasicek, O. (1977). An equilibrium characterization of the term structure. Journal of Financial Economics, 5(2):177-188.

Verdelhan, A. (2015). The share of systematic variation in bilateral exchange rates. Journal of Finance (forthcoming).

Welch, I. and Goyal, A. (2008). A comprehensive look at the empirical performance of equity premium prediction. Review of Financial Studies, 21(4):253-303. 
Table 1: Principal components analysis

\begin{tabular}{llll}
\hline & \multicolumn{3}{c}{ Share variance explained } \\
& First PC & Second PC & Third PC \\
\hline Norway & 0.905 & 0.082 & 0.011 \\
Sweden & 0.965 & 0.029 & 0.006 \\
Denmark & 0.955 & 0.039 & 0.005 \\
Japan & 0.866 & 0.116 & 0.016 \\
U.K. & 0.940 & 0.051 & 0.008 \\
Euro Core & 0.939 & 0.056 & 0.005 \\
Euro Periphery & 0.981 & 0.018 & 0.001 \\
Australia & 0.848 & 0.138 & 0.012 \\
South Africa & 0.885 & 0.072 & 0.022 \\
Mexico & 0.959 & 0.037 & 0.004 \\
Indonesia & 0.969 & 0.030 & 0.001 \\
U.S. & 0.902 & 0.081 & 0.016 \\
\hline
\end{tabular}

Notes: Principal components computed on SCDS contracts at four maturities: 1-, 3-, 5- and 10-year. Daily data over the period from January 2012 to March 2015. 
Table 2: Maximum likelihood parameters of the default risk term structure model

\begin{tabular}{|c|c|c|c|c|c|c|}
\hline & Norway & Sweden & Denmark & Japan & U.K. & E.U. Core \\
\hline \multirow[t]{2}{*}{$\kappa$} & 0.154 & 0.002 & 0.002 & 0.002 & 0.002 & 0.002 \\
\hline & $(0.105)$ & $(0.010)$ & $(0.008)$ & $(0.007)$ & $(0.006)$ & $(0.007)$ \\
\hline \multirow[t]{2}{*}{$\alpha$} & 0.066 & 0.201 & 0.271 & 0.204 & 0.181 & 0.279 \\
\hline & $(0.007)$ & $(0.018)$ & $(0.023)$ & $(0.025)$ & $(0.018)$ & $(0.026)$ \\
\hline \multirow[t]{2}{*}{$\sigma_{\varepsilon}$} & 0.144 & 0.207 & 0.262 & 0.426 & 0.289 & 0.350 \\
\hline & $(0.001)$ & $(0.001)$ & $(0.001)$ & $(0.002)$ & $(0.002)$ & $(0.002)$ \\
\hline \multirow{2}{*}{ Log lik } & 4.70 & 4.75 & 4.78 & 4.83 & 4.79 & 4.81 \\
\hline & $\begin{array}{c}\text { E.U. } \\
\text { Periphery }\end{array}$ & Australia & $\begin{array}{l}\text { South } \\
\text { Africa }\end{array}$ & Mexico & Indonesia & U.S. \\
\hline \multirow[t]{2}{*}{$\kappa$} & 0.002 & 0.185 & 0.169 & 0.204 & 0.065 & 0.002 \\
\hline & $(0.007)$ & $(0.027)$ & $(0.115)$ & $(0.050)$ & $(0.006)$ & $(0.057)$ \\
\hline \multirow[t]{2}{*}{$\alpha$} & 0.888 & 0.382 & 0.136 & 0.410 & 0.107 & 0.345 \\
\hline & $(0.060)$ & $(0.037)$ & $(0.012)$ & $(0.040)$ & $(0.010)$ & $(0.041)$ \\
\hline \multirow[t]{2}{*}{$\sigma_{\varepsilon}$} & 0.587 & 0.735 & 0.144 & 0.590 & 0.802 & 0.599 \\
\hline & $(0.003)$ & $(0.004)$ & $(0.001)$ & $(0.003)$ & $(0.005)$ & $(0.003)$ \\
\hline Log lik & 4.87 & 4.89 & 4.71 & 4.87 & 4.90 & 4.87 \\
\hline
\end{tabular}

Notes: Standard errors are in parentheses. 
Table 3: Summary statistics on SCDS premia and interest rates

\begin{tabular}{|c|c|c|c|c|c|c|c|c|c|c|}
\hline & \multicolumn{5}{|c|}{ SCDS premium (in bps) } & & \multicolumn{4}{|c|}{ Interest rates (in \%) } \\
\hline & & mean & $\max$ & $\min$ & std. dev. & & mean & $\max$ & $\min$ & std. dev. \\
\hline \multirow[t]{4}{*}{ Norway } & 1-year & 4.3 & 19.7 & 1.1 & 2.9 & 3-month & 1.71 & 2.89 & 1.00 & 0.40 \\
\hline & 3-year & 9.2 & 33.8 & 4.0 & 4.8 & & & & & \\
\hline & 5 -year & 17.7 & 44.9 & 10.6 & 6.3 & & & & & \\
\hline & 10-year & 31.9 & 55.0 & 24.0 & 5.5 & & & & & \\
\hline \multirow[t]{4}{*}{ Sweden } & 1-year & 5.2 & 45.5 & 1.5 & 6.1 & 3-month & 0.46 & 1.59 & -0.69 & 0.64 \\
\hline & 3-year & 11.9 & 62.4 & 5.0 & 10.5 & & & & & \\
\hline & 5 -year & 22.6 & 80.6 & 12.6 & 14.4 & & & & & \\
\hline & 10-year & 41.6 & 94.7 & 27.0 & 14.5 & & & & & \\
\hline \multirow[t]{4}{*}{ Denmark } & 1-year & 10.6 & 92.4 & 2.1 & 17.2 & 3-month & 0.25 & 1.01 & -0.44 & 0.32 \\
\hline & 3-year & 20.9 & 117.5 & 4.0 & 26.4 & & & & & \\
\hline & 5 -year & 36.2 & 138.3 & 13.1 & 33.0 & & & & & \\
\hline & 10-year & 59.9 & 155.4 & 34.1 & 32.5 & & & & & \\
\hline \multirow[t]{4}{*}{ Japan } & 1-year & 14.2 & 70.0 & 3.7 & 8.9 & 3 -month & -0.01 & 0.11 & -0.40 & 0.12 \\
\hline & 3-year & 33.8 & 118.3 & 13.5 & 17.8 & & & & & \\
\hline & 5 -year & 58.9 & 152.6 & 30.2 & 24.2 & & & & & \\
\hline & 10-year & 99.5 & 183.1 & 58.2 & 26.5 & & & & & \\
\hline \multirow[t]{4}{*}{ United Kingdom } & 1-year & 7.9 & 45.5 & 2.1 & 6.4 & 3-month & 0.67 & 1.09 & 0.46 & 0.17 \\
\hline & 3-year & 18.2 & 68.4 & 6.1 & 10.5 & & & & & \\
\hline & 5 -year & 34.6 & 99.6 & 15.4 & 17.6 & & & & & \\
\hline & 10-year & 60.4 & 119.1 & 35.2 & 18.3 & & & & & \\
\hline \multirow[t]{4}{*}{ Euro Core } & 1-year & 15.2 & 139.1 & 3.5 & 22.5 & 3-month & -0.07 & 0.17 & -0.50 & 0.16 \\
\hline & 3-year & 32.2 & 175.0 & 8.0 & 34.2 & & & & & \\
\hline & 5 -year & 54.8 & 200.5 & 20.0 & 42.3 & & & & & \\
\hline & 10-year & 85.9 & 212.9 & 47.3 & 39.6 & & & & & \\
\hline \multirow[t]{4}{*}{ Euro Periphery } & 1-year & 146.4 & 849.8 & 23.3 & 197.3 & 3-month & 0.69 & 3.72 & -0.25 & 0.86 \\
\hline & 3-year & 207.7 & 837.2 & 53.1 & 211.7 & & & & & \\
\hline & 5 -year & 235.5 & 778.6 & 78.2 & 188.1 & & & & & \\
\hline & 10-year & 260.9 & 684.4 & 121.9 & 147.1 & & & & & \\
\hline \multirow[t]{4}{*}{ Australia } & 1-year & 22.9 & 88.0 & 2.8 & 16.5 & 3-month & 3.03 & 4.91 & 2.31 & 0.65 \\
\hline & 3-year & 56.3 & 150.6 & 20.4 & 28.5 & & & & & \\
\hline & 5-year & 133.3 & 293.8 & 71.4 & 54.5 & & & & & \\
\hline & 10-year & 131.5 & 220.5 & 88.3 & 30.3 & & & & & \\
\hline \multirow[t]{4}{*}{ South Africa } & 1-year & 78.9 & 240.8 & 15.7 & 41.1 & 3-month & 6.02 & 7.97 & 5.02 & 0.68 \\
\hline & 3-year & 146.4 & 252.3 & 67.9 & 38.6 & & & & & \\
\hline & 5 -year & 208.9 & 391.6 & 121.7 & 54.2 & & & & & \\
\hline & 10-year & 246.1 & 335.7 & 171.9 & 28.0 & & & & & \\
\hline \multirow[t]{4}{*}{ Mexico } & 1-year & 40.9 & 92.8 & 15.1 & 14.9 & 3-month & 3.61 & 4.50 & 2.85 & 0.55 \\
\hline & 3-year & 79.0 & 164.5 & 31.5 & 26.2 & & & & & \\
\hline & 5 -year & 118.9 & 229.5 & 64.2 & 31.5 & & & & & \\
\hline & 10-year & 166.5 & 289.9 & 109.3 & 36.4 & & & & & \\
\hline \multirow[t]{4}{*}{ Indonesia } & 1-year & 49.8 & 130.9 & 10.8 & 22.9 & 3-month & 6.58 & 8.84 & 4.19 & 1.46 \\
\hline & 3-year & 108.3 & 206.2 & 59.3 & 30.9 & & & & & \\
\hline & 5 -year & 177.8 & 288.9 & 118.1 & 36.8 & & & & & \\
\hline & 10-year & 243.6 & 375.4 & 175.2 & 39.8 & & & & & \\
\hline \multirow[t]{4}{*}{ United States } & 1-year & 10.8 & 60.7 & 2.0 & 7.0 & 3-month & 0.07 & 0.34 & -0.01 & 0.07 \\
\hline & 3-year & 13.1 & 36.2 & 6.5 & 5.3 & & & & & \\
\hline & 5-year & 19.3 & 41.2 & 10.0 & 6.8 & & & & & \\
\hline & 10 -year & 30.6 & 62.5 & 20.1 & 7.6 & & & & & \\
\hline
\end{tabular}

Notes: Premia on sovereign credit default swaps for 1-, 3-, 5- and 10-year maturities (left panel) and 3-month interest rates (right panel) at daily frequency from January 2012 to March 2015. 
Table 4: Summary statistics on foreign exchange rates

\begin{tabular}{lcccc}
\hline & mean & max & min & std. dev. \\
Norwegian krone (NOK) & 6.00 & 7.48 & 5.46 & 0.35 \\
Swedish krona (SEK) & 6.72 & 7.86 & 6.29 & 0.30 \\
Danish krone (DKK) & 5.68 & 6.16 & 5.36 & 0.19 \\
Japanese yen (JPY) & 94.46 & 121.46 & 76.19 & 11.68 \\
British pound (GBP) & 0.63 & 0.67 & 0.58 & 0.02 \\
Euro (EUR) & 0.76 & 0.83 & 0.72 & 0.03 \\
Australian dollar (AUD) & 1.04 & 1.23 & 0.93 & 0.07 \\
South African rand (ZAR) & 9.57 & 11.76 & 7.44 & 1.16 \\
Mexican peso (MXN) & 13.22 & 15.63 & 11.98 & 0.67 \\
Indonesian rupiah (IDR) & 10725.8 & 13242.0 & 8870.0 & 1266.3 \\
\hline
\end{tabular}

Notes: Daily nominal spot exchange rate data from January 2012 to March 2015 from Datastream. All currencies are expressed in levels and in local currencies. 
Table 5: Out-of-sample predictability for daily exchange rates returns: default risk model relative to RW benchmark

\begin{tabular}{lcccccc}
\hline & $h=1$ & $\mathrm{p}$-value & $h=5$ & $\mathrm{p}$-value & $h=20$ & $\mathrm{p}$-value \\
\hline Norway & $\mathbf{0 . 9 9 3}$ & $(\mathbf{0 . 0 3 5})$ & $\mathbf{0 . 9 9 3}$ & $(\mathbf{0 . 0 3 4})$ & $\mathbf{0 . 9 9 2}$ & $(\mathbf{0 . 0 1 3})$ \\
Sweden & $\mathbf{0 . 9 9 6}$ & $(\mathbf{0 . 0 4 8})$ & $\mathbf{0 . 9 9 6}$ & $(\mathbf{0 . 0 2 4})$ & $\mathbf{0 . 9 9 6}$ & $(\mathbf{0 . 0 2 3})$ \\
Denmark & $\mathbf{0 . 9 9 5}$ & $(\mathbf{0 . 0 3 9})$ & $\mathbf{0 . 9 9 6}$ & $(\mathbf{0 . 0 4 9})$ & $\mathbf{0 . 9 9 6}$ & $(\mathbf{0 . 0 1 8})$ \\
Japan & $\mathbf{0 . 9 8 7}$ & $(0.121)$ & $\mathbf{0 . 9 8 9}$ & $(0.176)$ & $\mathbf{0 . 9 9 4}$ & $(0.351)$ \\
U.K. & 1.001 & $(0.752)$ & 1.003 & $(0.887)$ & 1.002 & $(0.898)$ \\
Euro Core & $\mathbf{0 . 9 9 5}$ & $(\mathbf{0 . 0 5 7})$ & $\mathbf{0 . 9 9 7}$ & $(0.101)$ & $\mathbf{0 . 9 9 6}$ & $(\mathbf{0 . 0 3 0})$ \\
Euro Periphery & $\mathbf{0 . 9 9 5}$ & $(\mathbf{0 . 0 3 2})$ & $\mathbf{0 . 9 9 8}$ & $(0.190)$ & 1.001 & $(0.643)$ \\
Australia & $\mathbf{0 . 9 9 4}$ & $(\mathbf{0 . 0 8 6})$ & $\mathbf{0 . 9 9 4}$ & $(\mathbf{0 . 0 7 9})$ & $\mathbf{0 . 9 9 2}$ & $(0.130)$ \\
South Africa & $\mathbf{0 . 9 9 7}$ & $(0.294)$ & $\mathbf{0 . 9 9 6}$ & $(0.259)$ & $\mathbf{0 . 9 9 7}$ & $(0.346)$ \\
Mexico & $\mathbf{0 . 9 9 6}$ & $(0.150)$ & $\mathbf{0 . 9 9 9}$ & $(0.443)$ & $\mathbf{0 . 9 9 1}$ & $(0.108)$ \\
Indonesia & $\mathbf{0 . 9 7 6}$ & $\mathbf{( 0 . 0 5 3 )}$ & 1.000 & $(0.509)$ & 1.005 & $(0.636)$ \\
\hline
\end{tabular}

Notes: The table reports the ratio of the MSPE of the default risk model relative to a RW benchmark, and the p-values for the CW test (see Clark and West (2007)) for $h=1, h=5$ and $h=20$ days ahead. The models are recursively estimated over a period spanning 2 January 2012 to 7 November 2013. The OOS evaluation period is 8 November 2013 to 11 March 2015. Ratios less than 1 are displayed in bold and indicate that the default risk model outperforms the benchmark model. P-values for the CW test of less than $10 \%$ are also displayed in bold and indicate that the difference is statistically significant. 
Table 6: Out-of-sample predictability for daily exchange rates returns: alternative default risk models relative to $\mathrm{RW}$ benchmark

\begin{tabular}{lcccccc}
\hline & \multicolumn{7}{c}{ Global SCDS } \\
\hline Norway & $h=1$ & $\mathrm{p}$-value & $h=5$ & $\mathrm{p}$-value & $h=20$ & p-value \\
Sweden & $\mathbf{0 . 9 9 2}$ & $\mathbf{( \mathbf { 0 . 0 3 6 } )}$ & $\mathbf{0 . 9 9 3}$ & $\mathbf{( \mathbf { 0 . 0 3 5 } )}$ & $\mathbf{0 . 9 9 2}$ & $\mathbf{( \mathbf { 0 . 0 2 5 } )}$ \\
Denmark & $\mathbf{0 . 9 9 2}$ & $\mathbf{( \mathbf { 0 . 0 1 1 } )}$ & $\mathbf{0 . 9 9 7}$ & $(0.131)$ & $\mathbf{0 . 9 9 7}$ & $\mathbf{( 0 . 0 9 1 )}$ \\
Japan & $\mathbf{0 . 9 9 4}$ & $\mathbf{( 0 . 0 2 1 )}$ & $\mathbf{0 . 9 9 7}$ & $(0.114)$ & $\mathbf{0 . 9 9 6}$ & $\mathbf{( 0 . 0 3 6 )}$ \\
U.K. & $\mathbf{0 . 9 8 8}$ & $(0.154)$ & $\mathbf{0 . 9 8 9}$ & $(0.157)$ & $\mathbf{0 . 9 9 6}$ & $(0.353)$ \\
Euro Core & $\mathbf{0 . 9 9 9}$ & $(0.395)$ & $\mathbf{0 . 9 9 9}$ & $(0.346)$ & 1.004 & $(0.952)$ \\
Euro Periphery & $\mathbf{0 . 9 9 4}$ & $\mathbf{( 0 . 0 2 7 )}$ & $\mathbf{0 . 9 9 7}$ & $(0.134)$ & $\mathbf{0 . 9 9 6}$ & $\mathbf{( 0 . 0 4 5 )}$ \\
Australia & $\mathbf{0 . 9 9 4}$ & $\mathbf{( 0 . 0 2 9 )}$ & $\mathbf{0 . 9 9 7}$ & $(\mathbf{0 . 0 9 4})$ & $\mathbf{0 . 9 9 5}$ & $\mathbf{( 0 . 0 2 8 )}$ \\
South Africa & $\mathbf{0 . 9 9 4}$ & $\mathbf{( 0 . 0 8 9 )}$ & $\mathbf{0 . 9 9 4}$ & $(\mathbf{0 . 0 9 6})$ & $\mathbf{0 . 9 9 6}$ & $(0.159)$ \\
Mexico & $\mathbf{0 . 9 9 4}$ & $(0.144)$ & $\mathbf{0 . 9 9 4}$ & $(0.162)$ & $\mathbf{0 . 9 9 6}$ & $(0.245)$ \\
Indonesia & $\mathbf{0 . 9 9 8}$ & $(0.116)$ & $\mathbf{0 . 9 9 9}$ & $(0.394)$ & $\mathbf{0 . 9 9 8}$ & $(0.172)$ \\
\hline
\end{tabular}

Notes: The alternative measure of default risk is a measure of global SCDS data. The table reports the ratio of the MSPE relative to a RW benchmark, and the p-values for the CW test (see Clark and West (2007)) for $h=1, h=5$ and $h=20$ days ahead. The model is recursively estimated over a period spanning 2 January 2012 to 7 November 2013. The OOS evaluation period is 8 November 2013 to 11 March 2015. Ratios less than 1 are displayed in bold and indicate that the default risk model outperforms the benchmark model. P-values for the CW test of less than $10 \%$ are also displayed in bold and indicate that the difference is statistically significant. 
Table 7: Out-of-sample predictability for daily exchange rates returns: default risk model relative to RW benchmark at weekly and monthly frequencies.

\begin{tabular}{lcccc}
\hline & Weekly & p-value & Monthly & p-value \\
\hline Norway & $\mathbf{0 . 9 6 6}$ & $\mathbf{( 0 . 0 5 2 )}$ & $\mathbf{0 . 8 3 6}$ & $\mathbf{( 0 . 0 3 0 )}$ \\
Sweden & $\mathbf{0 . 9 5 9}$ & $\mathbf{( 0 . 0 3 5 )}$ & $\mathbf{0 . 8 4 4}$ & $\mathbf{( 0 . 0 3 4 )}$ \\
Denmark & $\mathbf{0 . 9 8 3}$ & $(0.148)$ & $\mathbf{0 . 8 3 2}$ & $\mathbf{( 0 . 0 3 2 )}$ \\
Japan & $\mathbf{0 . 9 6 2}$ & $(0.303)$ & $\mathbf{0 . 9 9 5})$ & $(0.492)$ \\
U.K. & 1.009 & $(0.797)$ & 1.021 & $(0.665)$ \\
Euro Core & $\mathbf{0 . 9 8 8}$ & $(0.202)$ & $\mathbf{0 . 8 2 0}$ & $\mathbf{( 0 . 0 2 9})$ \\
Euro Periphery & 1.010 & $(0.672)$ & $\mathbf{0 . 7 9 9}$ & $\mathbf{( 0 . 0 1 9 )}$ \\
Australia & $\mathbf{0 . 9 6 3}$ & $\mathbf{( 0 . 0 6 9 )}$ & $\mathbf{0 . 8 8 1}$ & $\mathbf{( 0 . 0 8 2 )}$ \\
South Africa & $\mathbf{0 . 9 6 9}$ & $(0.192)$ & $\mathbf{0 . 9 8 7}$ & $(0.476)$ \\
Mexico & 1.003 & $(0.625)$ & $\mathbf{0 . 9 5 5}$ & $(0.348)$ \\
Indonesia & 1.002 & $(0.513)$ & 1.088 & $(0.626)$ \\
\hline
\end{tabular}

Notes: The table reports the ratio of the MSPE of the default risk model relative to a RW benchmark, and the p-values for the CW test (see Clark and West (2007)) for $h=1$-step-ahead forecast, obtained by using data at either weekly or monthly frequencies respectively. The models are recursively estimated over a period spanning 2 January 2012 to 7 November 2013. The OOS evaluation period is 8 November 2013 to 11 March 2015. End-ofweek or end-of-month data are considered. Ratios less than 1 are displayed in bold and indicate that the default risk model outperforms the benchmark model. 
Table 8: Out-of-sample predictability for daily exchange rates returns: interest rate model relative to RW benchmark

\begin{tabular}{lcccccc}
\hline & $h=1$ & p-value & $h=5$ & p-value & $h=20$ & p-value \\
\hline Norway & $\mathbf{0 . 9 8 5}$ & $(\mathbf{0 . 0 5 9})$ & $\mathbf{0 . 9 8 6}$ & $(\mathbf{0 . 0 6 9})$ & $\mathbf{0 . 9 8 6}$ & $(\mathbf{0 . 0 5 4})$ \\
Sweden & $\mathbf{0 . 9 8 5}$ & $(\mathbf{0 . 0 7 5})$ & $\mathbf{0 . 9 7 5}$ & $(\mathbf{0 . 0 1 7})$ & $\mathbf{0 . 9 7 7}$ & $(\mathbf{0 . 0 2 0})$ \\
Denmark & $\mathbf{0 . 9 9 9}$ & $(0.371)$ & 1.000 & $(0.489)$ & 1.008 & $(0.969)$ \\
Japan & $\mathbf{0 . 9 9 7}$ & $(0.434)$ & 1.002 & $(0.527)$ & 1.018 & $(0.855)$ \\
U.K. & 1.002 & $(0.846)$ & 1.002 & $(0.879)$ & 1.002 & $(0.785)$ \\
Euro Core & $\mathbf{0 . 9 8 4}$ & $(\mathbf{0 . 0 3 9})$ & $\mathbf{0 . 9 8 9}$ & $\mathbf{( 0 . 0 4 0 )}$ & 1.004 & $(0.922)$ \\
Euro Periphery & $\mathbf{0 . 9 8 6}$ & $(\mathbf{0 . 0 2 0})$ & $\mathbf{0 . 9 8 6}$ & $\mathbf{( 0 . 0 1 3 )}$ & $\mathbf{0 . 9 8 5}$ & $\mathbf{( 0 . 0 1 0 )}$ \\
Australia & $\mathbf{0 . 9 9 4}$ & $(0.160)$ & $\mathbf{0 . 9 9 4}$ & $(0.141)$ & $\mathbf{0 . 9 9 5}$ & $(0.179)$ \\
South Africa & 1.006 & $(0.819)$ & 1.010 & $(0.881)$ & 1.002 & $(0.645)$ \\
Mexico & $\mathbf{0 . 9 9 6}$ & $(0.366)$ & $\mathbf{0 . 9 9 2}$ & $(0.247)$ & $\mathbf{0 . 9 9 1}$ & $(0.183)$ \\
Indonesia & 1.006 & $(0.615)$ & 1.012 & $(0.717)$ & 1.040 & $(0.970)$ \\
\hline
\end{tabular}

Notes: The table reports the ratio of the MSPE of the interest rate model relative to a RW benchmark, and the p-values for the CW test (see Clark and West (2007)) for $h=1, h=5$ and $h=20$ days ahead. The models are recursively estimated over a period spanning 2 January 2012 to 7 November 2013. The OOS evaluation period is 8 November 2013 to 11 March 2015. Ratios less than 1 are displayed in bold and indicate that the default risk model outperforms the benchmark model. P-values for the CW test of less than $10 \%$ are also displayed in bold and indicate that the difference is statistically significant. 
Figure 1: Sovereign credit default swap premia per country

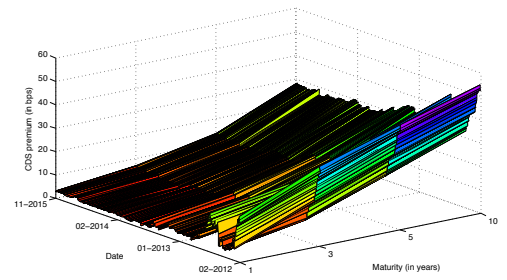

(a) Norway

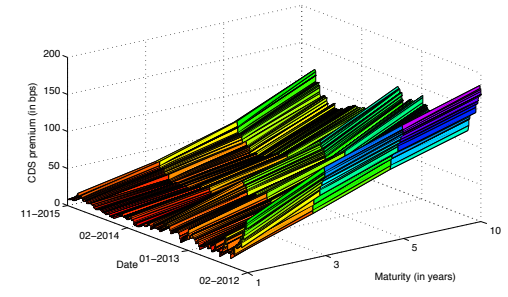

(d) Japan

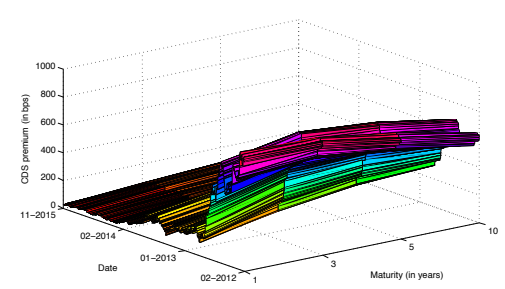

(g) E.U. Periphery

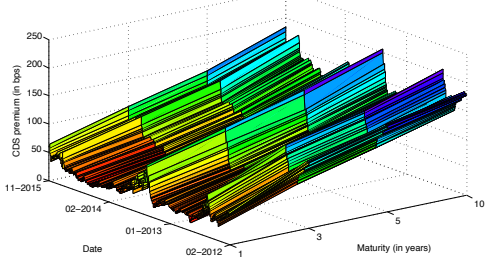

(j) Mexico

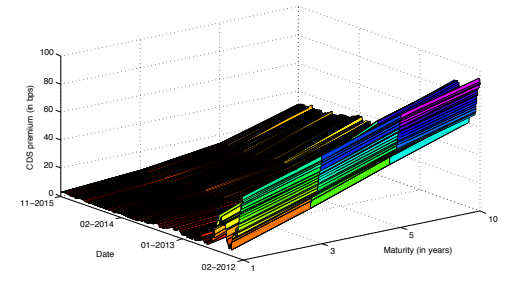

(b) Sweden

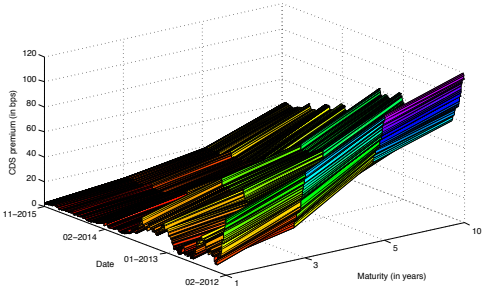

(e) United Kingdom

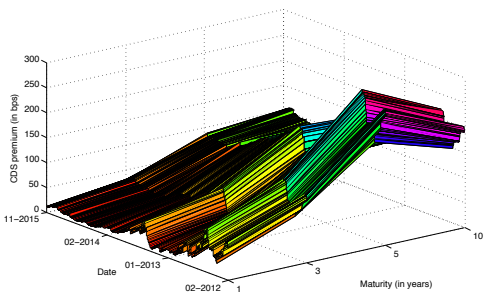

(h) Australia

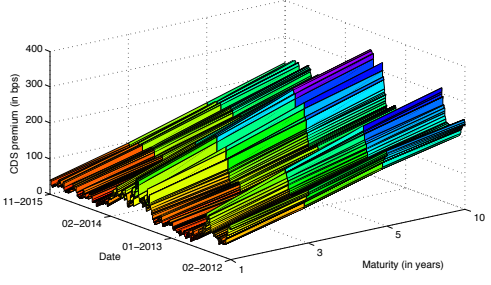

(k) Indonesia

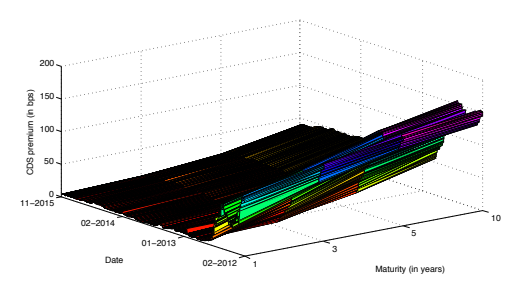

(c) Denmark

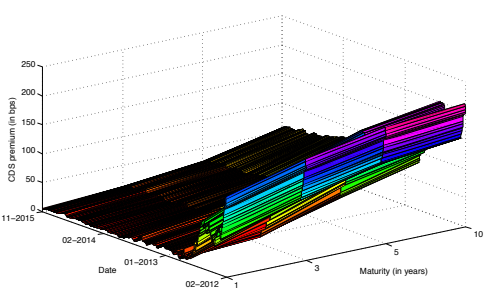

(f) E.U. Core

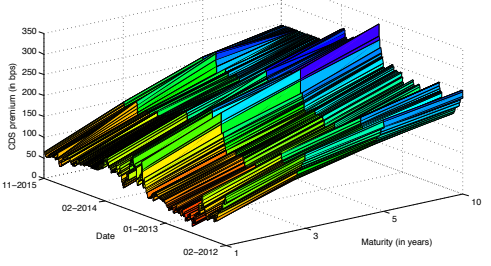

(i) South Africa

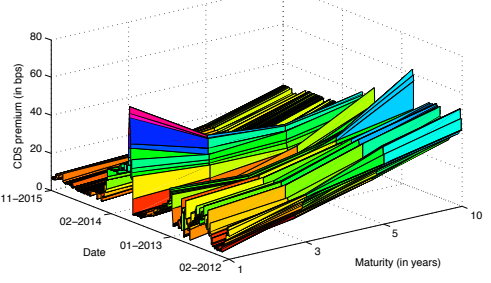

(1) United States 
Figure 2: Cumulative squared prediction error difference for $h=1$

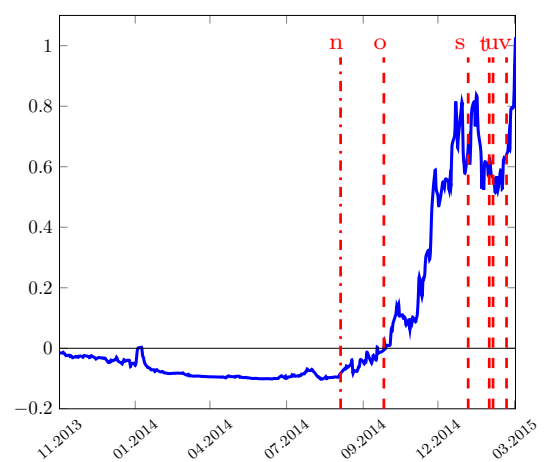

(a) Norway

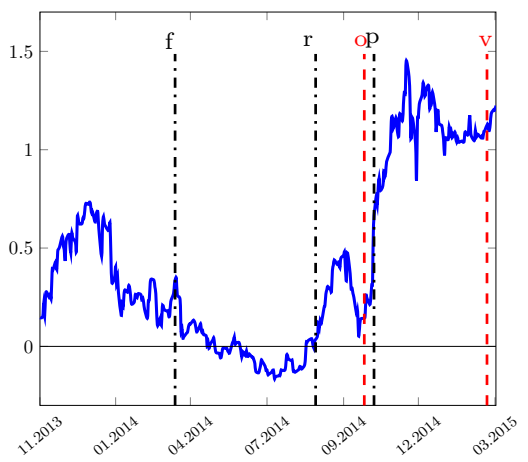

(d) Japan

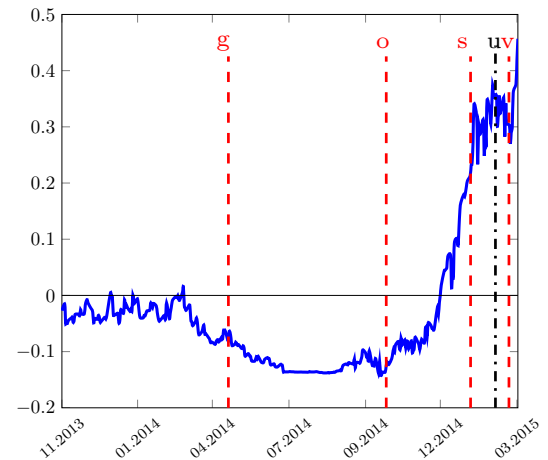

(b) Sweden

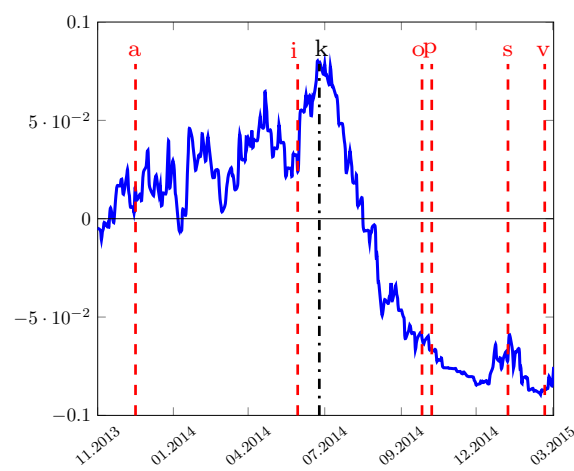

(e) United Kingdom

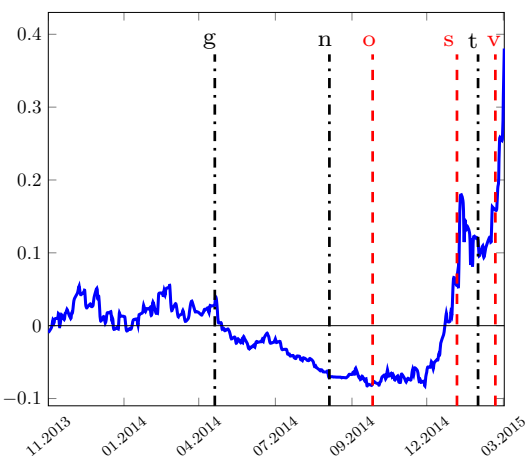

(c) Denmark

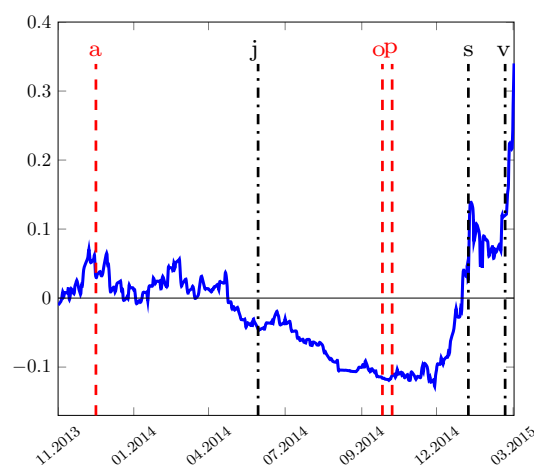

(f) Euro Core

-... domestic events - - - foreign events

Figure 2 reports the CSPED for forecasting at horizon $h=1$ :

$$
C S P E D_{k, t+1}=\sum_{s=\underline{t}}^{t} \widehat{f}_{k, s+1},
$$

where $\widehat{f}_{k, t+1}=e_{R W, t+1}^{2}-e_{k, t+1}^{2}$ with $e_{R W, t+1}^{2}$ the squared error of the RW model to predict $y_{t+1}$ and $e_{k, t+1}^{2}$ the squared error of one of the $k$ alternative models. Increases in $C S P E D_{k, t+1}$ indicate that the alternative model predicts better at the OOS observation $t+1$. The alternative model is the linear regression with the predictor based on CDS data. Timeline legends: (a) 18/12/13, Fed announcement of tapering by steps; (b) 01/01/14, tax reform is implemented in Mexico; (c) 23/01/14, Spain exits bailout; (d) 29/01/14, South African Reserve Bank raises repo rate; (e) 02/14, budget speech in South Africa with good economic forecast; (f) 01/04/14, Japan VAT rate hike; (g) 25/04/14, Danish Central Bank (DCB) raises deposit rates to 0.05; (h) 18/05/14, Portugal exits bailout mechanism; (i) 23/06/14, sharp drop in oil prices; (j) 11/06/14, ECB cuts rates to negative; (k) 01/07/14, U.K. GDP growth reaches its peak since the crisis; (l) 09/07/14, presidential elections in Indonesia; (m) 07/08/14, Mexico's energy reforms become law; (n) 05/09/14, DCB cuts rates to negative; (o) 28/10/14, end of Fed asset purchases and Sveriges Riksbank (SR) hits the ZLB; (p) 30/10/14, BoJ extends QE program; (q) 18/11/14, Bank of Indonesia raises benchmark rate; (r) 2014Q3, Japan falls back into recession; (s) 22/01/15, ECB announcement of start of QE; (t) 06/02/15, DCB undercover QE by cutting rates deeper into negative territory; (u) 12/02/15, SR announces government bond purchases; (v) 09/03/15, ECB starts QE program. 
Figure 2 (cont.): Cumulative squared prediction error difference for $h=1$

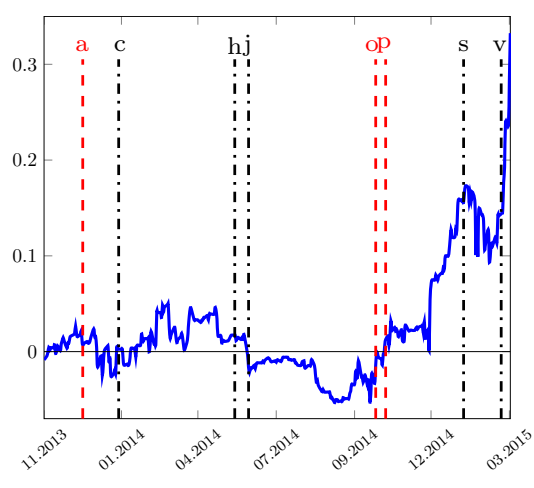

(a) Euro Periphery

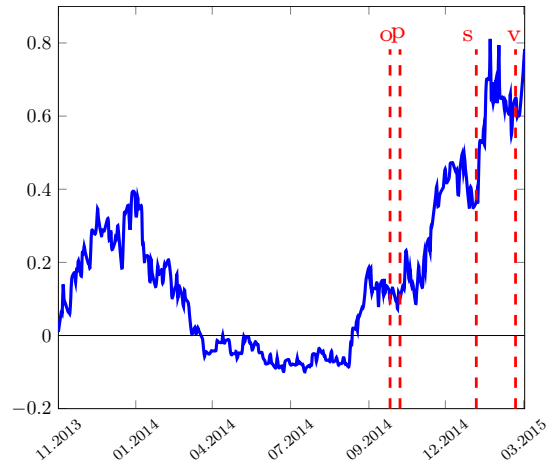

(b) Australia

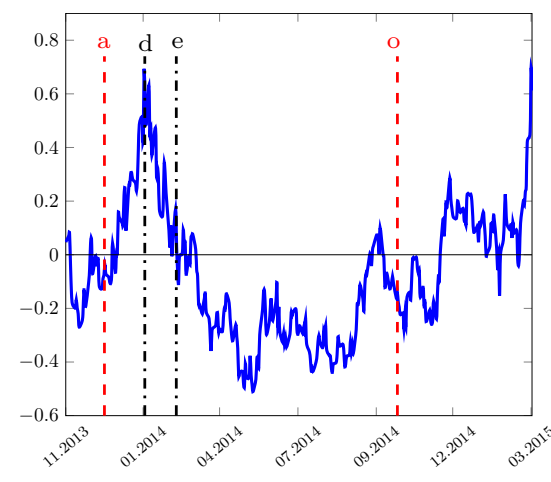

(c) South Africa

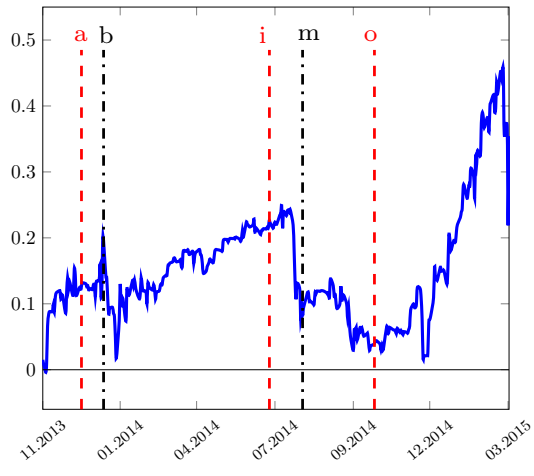

(d) Mexico

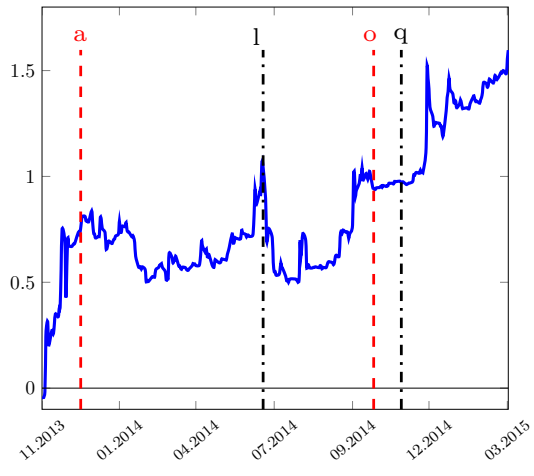

(e) Indonesia

-.-. domestic events =-- foreign events

See footnote to Figure 2. 


\section{Appendix A: Moments of the factors}

Here we show the conditional and unconditional mean and variance used in the CDS spreads term structure model. The conditional moments of the factors are used in the construction of the quasi-likelihood function that is maximized in the Kalman filter estimation. The unconditional moments serve to initialize the process.

The conditional mean and variance are as follows:

$$
\begin{gathered}
E\left(F_{t+h} \mid F_{t}\right)=\theta+e^{\Lambda h}\left(F_{t}-\theta\right) \\
\operatorname{Var}\left(F_{t+h} \mid F_{t}\right)=\frac{1-e^{-(2 \kappa) h}}{2 \kappa} a
\end{gathered}
$$

In turn, the unconditional mean and variance are as follows:

$$
\begin{gathered}
E\left(F_{t+s}\right)=\theta \\
\operatorname{Var}\left(F_{t}\right)=\frac{a}{2 \kappa}
\end{gathered}
$$

For a derivation, see de Jong (2000).

\section{Appendix B: Solutions to the Riccati equations}

In this section, we describe the solutions to the functions $\Phi(t, u), \Psi(t, u), \Phi_{u}(t, u)$ and $\Psi_{u}(t, u)$ in eq.(4) that solve the expectations in the CDS pricing equation, eq.(3), given by Duffie and Garleanu (2001):

$$
\begin{aligned}
E\left[e^{\int_{0}^{t} q \lambda(s) \partial s} \lambda_{t} e^{u \lambda_{t}}\right]=e^{\Phi(t, u)+\Psi(t, u) \lambda_{t}}\left[\Phi_{u}(t, u)+\Psi_{u}(t, u) \lambda_{t}\right] & \\
\Phi(t, u) & =\frac{m\left(a_{1} c_{1}-d_{1}\right)}{b_{1} c_{1} d_{1}} \log \frac{c_{1}+d_{1} e^{b_{1} t}}{c_{1}+d_{1}}+\frac{m}{c_{1}} t \\
\Psi(t, u) & =\frac{1+a_{1} e^{b_{1} t}}{c_{1}+d_{1} e^{b_{1} t}} \\
\Phi_{u}(t, u) & =\frac{\partial \Phi(t, u)}{\partial u} \\
\Psi_{u}(t, u) & =\frac{\partial \Psi(t, u)}{\partial u}
\end{aligned}
$$

where 


$$
\begin{aligned}
& c_{1}=\frac{-n+\sqrt{n^{2}-2 p q}}{2 q} \\
& d_{1}=\left(1-c_{1} u\right) \frac{n+p u+\sqrt{(n+p u)^{2}-p\left(p u^{2}+2 n u+2 q\right)}}{2 n u+p u^{2}+2 q} \\
& a_{1}=\left(d_{1}+c_{1}\right) u-1 \\
& b_{1}=\frac{d_{1}\left(n+2 q c_{1}\right)+a_{1}\left(n c_{1}+p\right)}{a_{1} c_{1}-d_{1}}
\end{aligned}
$$

The solutions of the derivative functions $\Phi_{u}(t, u)$ and $\Psi_{u}(t, u)$ are obtained from the Symbolic Toolbox from MATLAB.

\section{Appendix C: State-space representation of the CDS model}

For the term structure model of the CDS spreads, we estimate a single latent factor model with a nonlinear observation equation which requires the use of the extended Kalman filter for linearization before estimation. Here we outline the state-space representation of our discretetime reduce form model given by eqs.(7) and (8).

The state-space system with state vector $F_{t}$ is given by

$$
\begin{array}{rlrl}
y_{t} & =B\left(F_{t}\right)+\varepsilon_{t} & \varepsilon_{t} & \sim N(0, H) \\
F_{t} & =\Phi^{0}+\Phi^{1} F_{t-1}+\eta_{t} & \eta_{t} \sim N(0, Q)
\end{array}
$$

where

$$
\begin{gathered}
y_{t}=\left(\begin{array}{c}
Y_{\tau_{1} t} \\
Y_{\tau_{3} t} \\
Y_{\tau_{5} t} \\
Y_{\tau_{10} t}
\end{array}\right), \quad F_{t}=\lambda_{t}, \quad \varepsilon_{t}=\left(\begin{array}{c}
\varepsilon_{\tau_{1} t} \\
\varepsilon_{\tau_{3} t} \\
\varepsilon_{\tau_{5} t} \\
\varepsilon_{\tau_{10} t}
\end{array}\right), \quad \eta_{t}=\eta_{t} \\
\Phi^{0}=\theta\left(1-e^{-\kappa \Delta t}\right), \quad \Phi^{1}=e^{-\kappa \Delta t} \\
Q=\operatorname{Var}\left[F_{t} \mid \hat{F}_{t-1}\right], \quad H=\left(\begin{array}{cccc}
\sigma_{\varepsilon_{\tau_{1} t}}^{2} & 0 & 0 & 0 \\
0 & \sigma_{\varepsilon_{\tau_{3} t}}^{2} & 0 & 0 \\
0 & 0 & \sigma_{\varepsilon_{\tau_{5} t}}^{2} & 0 \\
0 & 0 & 0 & \sigma_{\varepsilon_{\tau_{10}}}^{2}
\end{array}\right)
\end{gathered}
$$


The state vector is initialized with the unconditional moments given in Appendix A.

For the implementation of the extended Kalman filter, the observation equation, eq.(7), is linearized using a first-order Taylor expansion around the predicted state $\lambda_{t \mid t-1}$, as follows:

$$
\begin{gathered}
y_{t}=c d s\left(\lambda_{t}, \Theta\right)+\varepsilon_{t} \\
y_{t}=c d s\left(\lambda_{t \mid t-1}, \Theta\right)+\left.\frac{\partial c d s(\lambda)}{\partial \lambda}\right|_{\lambda=\lambda_{t \mid t-1}}+\varepsilon_{t}
\end{gathered}
$$

Re-writing $c d s(\lambda, \Theta)$ in function notation, we get:

$$
\begin{gathered}
c d s(\lambda, \Theta)=(1-\pi) \frac{f(\lambda)}{g(\lambda)+h(\lambda)} \\
\frac{\partial c d s(\lambda)}{\partial \lambda}=(1-\pi) \frac{\frac{\partial f(\lambda)}{\partial \lambda}[g(\lambda)+h(\lambda)]+f(\lambda)\left[\frac{\partial g(\lambda)}{\partial \lambda}+\frac{\partial h(\lambda)}{\partial \lambda}\right]}{[g(\lambda)+h(\lambda)]^{2}}
\end{gathered}
$$

where,

$$
\begin{aligned}
\frac{\partial f(\lambda)}{\partial \lambda} & =(1-\pi) \int_{t}^{\tau}\left\{\frac{\partial}{\partial \lambda} E_{t}^{\mathbb{Q}}\left[e^{-\int_{t}^{v} \lambda_{s} \partial s} \lambda_{v}\right]\right\} \partial v \\
\frac{\partial}{\partial \lambda} E_{t}^{\mathbb{Q}}\left[e^{-\int_{t}^{v} \lambda_{s} \partial s} \lambda_{v}\right] & =\frac{\partial}{\partial \lambda}\left\{e^{\Phi^{\lambda}(v-t, 0)+\Psi^{\lambda}(v-t, 0) \lambda_{t}}\left[\Phi_{u}^{\lambda}(v-t, 0)+\Psi_{u}^{\lambda}(v-t, 0) \lambda_{t}\right]\right\} \\
& =\Psi^{\lambda}(v-t, 0) E_{t}^{\mathbb{Q}}\left[e^{-\int_{t}^{v} \lambda_{s} \partial s} \lambda_{v}\right]+\Psi_{u}^{\lambda}(v-t, 0) e^{\Phi^{\lambda}(v-t, 0)+\Psi^{\lambda}(v-t, 0) \lambda_{t}} \\
& =\Psi^{\lambda}(v-t, 0) e^{\Phi^{\lambda}(v-t, 0)+\Psi^{\lambda}(v-t, 0) \lambda_{t}}\left[\Phi_{u}^{\lambda}(v-t, 0)+\Psi_{u}^{\lambda}(v-t, 0) \lambda_{t}\right] \\
& +\Psi_{u}^{\lambda}(v-t, 0) e^{\Phi^{\lambda}(v-t, 0)+\Psi^{\lambda}(v-t, 0) \lambda_{t}} \\
\frac{\partial g(\lambda)}{\partial \lambda} & =\frac{1}{4} \sum_{j=1}^{4 \tau} \frac{\partial}{\partial \lambda} E_{t}^{\mathbb{Q}}\left[e^{-\int_{t}^{\frac{1}{4} j} \lambda_{s} \partial s}\right] \\
\frac{\partial}{\partial \lambda} E_{t}^{\mathbb{Q}}\left[e^{-\int_{t}^{\frac{1}{4} j} \lambda_{s} \partial s}\right] & =\frac{\partial}{\partial \lambda}\left\{e^{\Phi^{\lambda}(v-t, 0)+\Psi^{\lambda}(v-t, 0) \lambda_{t}}\right\} \\
& =\Psi^{\lambda}(v-t, 0) E_{t}^{\mathbb{Q}}\left[e^{-\int_{t}^{v} \lambda_{s} \partial s}\right] \\
& =\Psi^{\lambda}(v-t, 0)\left[e^{\Phi^{\lambda}(v-t, 0)+\Psi^{\lambda}(v-t, 0) \lambda_{t}}\right]
\end{aligned}
$$




$$
\begin{aligned}
f(\lambda) & =(1-\pi) \int_{t}^{\tau}\left\{E_{t}^{\mathbb{Q}}\left[e^{-\int_{t}^{v} \lambda_{s} \partial s} \lambda_{v}\right]\right\} \partial v \\
E_{t}^{\mathbb{Q}}\left[e^{-\int_{t}^{v} \lambda_{s} \partial s} \lambda_{v}\right] & =e^{\Phi^{\lambda}(v-t, 0)+\Psi^{\lambda}(v-t, 0) \lambda_{t}}\left[\Phi_{u}^{\lambda}(v-t, 0)+\Psi_{u}^{\lambda}(v-t, 0) \lambda_{t}\right] \\
g(\lambda) & =\frac{1}{4} \sum_{j=1}^{4 \tau} E_{t}^{\mathbb{Q}}\left[e^{-\int_{t}^{\frac{1}{4} j} \lambda_{s} \partial s}\right] \\
E_{t}^{\mathbb{Q}}\left[e^{-\int_{t}^{v} \lambda_{s} \partial s}\right] & =e^{\Phi^{\lambda}(v-t, 0)+\Psi^{\lambda}(v-t, 0) \lambda_{t}} \\
h(\lambda) & =\int_{t}^{\tau}\left\{E_{t}^{\mathbb{Q}}\left[e^{-\int_{t}^{\frac{1}{4} j} \lambda_{s} \partial s} \lambda_{v}\right]\left(v-T_{I(v)}\right)\right\} \partial v \\
E_{t}^{\mathbb{Q}}\left[e^{-\int_{t}^{v} \lambda_{s} \partial s} \lambda_{v}\right] & =e^{\Phi^{\lambda}(v-t, 0)+\Psi^{\lambda}(v-t, 0) \lambda_{t}}\left[\Phi_{u}^{\lambda}(v-t, 0)+\Psi_{u}^{\lambda}(v-t, 0) \lambda_{t}\right] \\
\frac{\partial h(\lambda)}{\partial \lambda} & =\int_{t}^{\tau}\left\{\frac{\partial}{\partial \lambda} E_{t}^{\mathbb{Q}}\left[e^{-\int_{t}^{v} \lambda_{s} \partial s} \lambda_{v}\right]\left(v-T_{I(v)}\right)\right\} \partial v \\
\frac{\partial \partial}{\partial \lambda} E_{t}^{\mathbb{Q}}\left[e^{-\int_{t}^{v} \lambda_{s} \partial s} \lambda_{v}\right] & =\Psi^{\lambda}(v-t, 0) e^{\Phi^{\lambda}(v-t, 0)+\Psi^{\lambda}(v-t, 0) \lambda_{t}}\left[\Phi_{u}^{\lambda}(v-t, 0)+\Psi_{u}^{\lambda}(v-t, 0) \lambda_{t}\right] \\
& +\Psi_{u}^{\lambda}(v-t, 0) e^{\Phi^{\lambda}(v-t, 0)+\Psi^{\lambda}(v-t, 0) \lambda_{t}}
\end{aligned}
$$

